\title{
Criticisms of an Evolutionary Hypothesis about Race Differences: A Rebuttal to Rushton's Reply
}

\author{
Michael Lynn, University of Missouri-Columbia
}

\begin{abstract}
Rushton's (1989) response failed to address many of my criticisms, cited the relevant literature in a biased manner, and misrepresented both theory and data. His hypothesis about race differences on the $r / K$ continuum should be rejected on the grounds that (a) the differences between $r$ and $K$ selection have little effect on larger mammals like man; (b) the literature reviews supporting this hypothesis are biased and many nonsupportive studies exist; (c) the hypothesis's assumption that the claimed race differences are functionally related to reproduction is implausible and unsupported; and (d) the race differences predicted by this hypothesis can be explained by environmental causes.
\end{abstract}

Rushton and Bogaert $(1987,1988)$ applied Rushton's (1985) Differential K theory to race differences in sexuality. According to them, blacks evolved a relatively $r$ reproductive strategy which is characterized by higher birth rates, less parental care, greater sexual permissiveness and precocity, larger genitalia, lower intelligence, shorter life spans, and less altruism. Orientals supposedly evolved a relatively $\mathrm{K}$ reproductive strategy which is characterized by lower birth rates, more parental care, less sexual permissiveness and precocity, etc. Whites were thought to fall between blacks and Orientals on this $r / K$ continuum.

I criticized Rushton and Bogaert's $(1987,1988)$ articles on four grounds (Lynn, 1989). First, they did not explain why natural selection would have favored the different reproductive strategies they attributed to different races. Second, their data on race differences were suspect because their literature review was selective and their original analysis was based on self-reports. Third, they provided no evidence that the race differences cited had any effects on reproduction or that sexual restraint was a K characteristic. Finally, they did not adequately rule out environmental explanations for their data. Rushton's (1989) response to these criticisms was, in effect, a new paper that he acknowledged went "beyond the data contained in the critiqued articles." However, this response fails to address many of my original criticisms, is selective in its review of relevant literatures, and misrepresents both theory and data. The specific problems with Rushton's responses to each of my four criticisms are discussed below. 


\section{Explanation for Race Differences in $\mathrm{r}$ and $\mathrm{K}$}

Rushton and Bogaert's (1987) hypothesis that the different races evolved different reproductive strategies assumes that there was differential natural selection for the different races. Thus, I criticized these authors for failing to provide a plausible explanation of why natural selection favored a relatively $r$ reproductive strategy for blacks and a relatively K reproductive strategy for Orientals (Lynn, 1989). Rushton (1989) responded to this criticism with three arguments. These arguments are discussed in turn below.

Use of $r$ and $K$ as Descriptors

First, Rushton (1989) pointed out that he wanted to use $r$ and $K$ as descriptors and sought to postpone discussion of the selection pressures that brought them about. However, Rushton (1989; Rushton \& Bogaert, 1987, 1988) used $r$ and K strategies as more than just descriptors. He used evolutionary theory about $r$ and $\mathrm{K}$ strategies to predict the covariation of numerous attributes and he explicitly argued that the explanation for this covariation was genetic. It is this use of the $\mathrm{r} / \mathrm{K}$ continuum to predict and explain race differences that assumes differential natural selection for the races. This assumption is implausible and needs to be justified.

\section{Evolution of $r$ and $K$ without Natural Selection}

Second, Rushton (1989) argued that $r$ and K may have evolved independently of natural selection. He (mis)used Brooks and Wiley's (1986) theory of evolution as entropy to suggest (a) that evolution is directed from r-type organisms to K-type organisms, and (b) that blacks are less evolved (more primitive) than whites who are less evolved than Orientals. Brooks and Wiley (1986) believe that evolution is an entropic process constrained by intrinsic historical and developmental factors as well as by natural selection. This theory suggests that a loss of complexity in one of the three biological means of dissipating energy and information i.e., in homeostasis, ontogeny, or replication-must be compensated for by an increase in the complexity of another of these dissipative pathways. This principle of compensatory change means that the covariation of body size, metabolic rate, and fecundity predicted by $r$ and $\mathrm{K}$ theory is the result of physical law rather than natural selection alone (Brooks \& Wiley, 1986; O'Grady, 1982). However, the principle of compensatory change does not require the covariation of the many other traits (e.g., intelligence, genitalia size, intercourse frequency, altruism, etc.) that Rushton associates with the $\mathrm{r} / \mathrm{K}$ continuum. Moreover, this theory neither states nor implies that evolution is directed from r-type organisms to K-type organisms (D. R. Brooks, personal 
communication, June 27,1988$)$. Thus, Rushton cannot legitimately use this theory to argue that Orientals are more $\mathrm{K}$ than whites and blacks because they are more evolved (or to argue that Orientals are more evolved because they are more $\mathrm{K}$ ).

Selection Scenario for Race Differences in $r$ and $K$

Rushton's (1989) third argument was that harsh arctic conditions during the ice age favored a K reproductive strategy and that exposure to these cold conditions was greatest for Orientals, followed by whites and then blacks. This argument disregards the very literature on $\mathrm{r}$ and $\mathrm{K}$ selection that Rushton used to build his theory. Current theory about $r$ and $\mathrm{K}$ selection has its origins in the work of Dobzhansky (1950), who suggested that natural selection operates differently in tropical than in temperate areas. He argued that mortality in temperate climates is affected by physical factors, such as severe storms, that are independent of population density. In these relatively unstable environments, natural selection favors those that take advantage of favorable short-term conditions by having many, rapidly maturing offspring. In contrast, tropical areas have more stable climates where mortality is population dependent. These conditions favor those that invest time and care in a small number of offspring. McArthur and Wilson (1967) labeled these two types of selection as "r selection" and "K selection," respectively. These types of selection are not limited to temperate and tropical areas-r selection operates on any opportunistic population in unstable, rarefied environments while $\mathrm{K}$ selection operates on any equilibrium population in stable, population dense environments (Pianka, 1970, 1978).

Rushton's (1989) argument that harsh, cold conditions during the last ice age favored K selection for Orientals and (to a lesser extent) whites is obviously at odds with the biological theory described above. It is not the harshness or temperature of an environment that makes for $\mathrm{r}$ selection or $\mathrm{K}$ selection; it is the environment's climatic stability and population density that produce one or the other type of selection. Thus, if anything, Rushton's scenario suggests that blacks should be more K than whites and Orientals who evolved in less stable and less populated environments. However, the kinds of year-to-year climatic changes that favor $r$ selection have a smaller impact on large mammals like man, so the predictions of $\mathrm{r}$ and $\mathrm{K}$ theory do not apply within these species (Richard, 1985).

\section{Race Differences in $\mathrm{r}$ and $\mathrm{K}$ Characteristics}

Rushton and Bogaert (1987) hypothesized that there were reliable race differences in a variety of attributes associated with $r$ selection and $\mathrm{K}$ selection. I criticized their data regarding such race differences because their literature review was selective and their original analyses involved self-report 
data (Lynn, 1989). Rushton (1989) responded that charges of selectivity cannot hold up given the near unanimous support he found for his predictions. He also pointed out that Weinberg and Williams (1988) replicated many of his observations about race differences in sexuality. These arguments are critically evaluated below.

Unanimity of Support for Predictions

Rushton's (1988) claim that he would not have found such unanimous support for his many predictions if the predicted race differences were not real is ridiculous. To begin with, the evidence is not as unanimously supportive of Rushton's predictions as he claims (see Lynn, 1989). Moreover, the supportive evidence that Rushton (1989; Rushton \& Bogaert, 1987, 1988) does report may be biased.

First, selectivity in the race differences examined may have biased the results in favor of Rushton and Bogaert's (1987) theory. Biologists (e.g., Barash, 1977; Daly \& Wilson, 1978; Pianka, 1970; Wilson, 1980) have argued that K selection favors a huger body size than does $r$ selection, yet Rushton and Bogaert (1987) did not list body size in their table of $r$ - and K-selected traits. Is this because they would have had a hard time proving that for body size Orientals > whites > blacks? In addition, Rushton and Bogaert (1987) follow Barash (1977) in listing altruism as a K-selected trait yet they do not review research on race differences in helping. Rushton has worked in the area of altruism so is undoubtedly aware that there are no race differences in helping after controlling for race of helpee (Gaertner \& Bickman, 1971; Wispe \& Freshly, 1971). Is that why the helping literature is ignored in their articles? The point is that Rushton and Bogaert (1987) may have unconsciously selected and examined only those hypotheses that they felt would be supported by data.

Second, selectivity in the studies discussed may have biased the results of Rushton and Bogaert's (1987) review. Recent works on the methodology of literature reviewing point out the importance of locating all the relevant research on a topic (Cooper, 1984; Rosenthal, 1984). Failure to do this can bias the results of a review and can lead to incorrect conclusions. Rushton and Bogaert (1987) did not conduct a comprehensive review, so it is possible that their review misrepresents some of the literature they sampled. Such a bias is certainly evident in Rushton's (1989) citation of data on race differences in intelligence and fecundity.

Finally, much of the original research on race differences may be biased in favor of Rushton and Bogaert's (1987) hypotheses. Rushton and Bogaert's (1987) predictions are consonant with many stereotypes about blacks and Orientals. Such stereotypes and expectations have been shown to bias research results even when the researchers are thought to have tried to be impartial (see Gould, 1981). 
Since Rushton and Bogaert (1987) did not critically evaluate the studies they reviewed, it is not clear whether those studies reflect real race differences or cultural stereotypes about the races.

\section{Replication of Race Differences in Sexuality}

Weinberg and Williams (1988), like Rushton and Bogaert (1988), found race differences in sexual attitudes and behavior even after controlling for education. However, they did not examine race differences in physical characteristics or physiological maturation, so their article only partially supports Rushton and Bogaert's (1987) findings. Moreover, Weinberg and Williams' (1988) replication does not present any new data; it merely reanalyzes existing research-including the Kinsey data Rushton and Bogaert $(1987,1988)$ used. Wyatt (in press-a) has argued that most of the existing research on ethnic differences in sexual behavior suffers from one or more of the following problems: (1) researchers have often sacrificed representativeness of the sample for large numbers of subects; (b) researchers have often compared ethnic and nonethnic groups that are dissimilar; (c) researchers have often classified members of different ethnic groups together under the label "blacks"; and (d) researchers have often been insensitive to subjects by, for example, using white male interviewers to interview black and white subjects of both sexes. The Kinsey data reanalyzed by both Rushton and Bogaert (1987) and Weinberg and Williams (1988) suffer from all four of these problems (Wyatt, in press-a). A recent study designed to avoid these problems found no ethnic differences in age of women's first coitus (Wyatt, in press-b).

Race Differences in Brain Size and Intelligence

In criticizing the adequacy of Rushton and Bogaert's (1987) data on race differences, I pointed out that Gould (1981) has discredited race differences in cranial capacity and brain size. Rushton (1989) responded by reanalyzing Gould's (1981) reanalysis of Morton's data, by discussing Tobias' (1970) calculations of race differences in excess neurons, and by citing Ho, Roessman, Straumfjord, and Monroe's (1980a, 1980b) autopsy data on race differences in brain weight. These analyses and data are discussed below.

Rushton (1989) argued that the corrected values for Morton's data (in Gould, 1981) show his predicted rank orderings of the races-i.e., Orientals $>$ whites $>$ blacks. However, the difference he reports between Orientals and whites is due to his inclusion of Ancient Caucasians (who were presumably smaller than Modern Caucasians) in the white category. No comparable groups of Ancient Mongoloids were included in the Oriental category. This inappropriate aggregation of subsamples to support hypotheses is precisely the sort of bias that Gould (1981) points out in Morton's original 
analyses. Moreover, the small race differences evident in these data are meaningless given the probable error component in the means and the unrepresentativeness of the samples.

Rushton (1989) also aggregated Tobias' (1970) calculations of excess neurons (i.e., the number of cortical neurons in excess of those needed for body functioning) and found that Orientals have more excess neurons than whites who have more than blacks. There are several problems with this analysis. The formulas used to calculate excess neurons are based on empirical relationships between neuron density and brain weight, cortical volume and brain weight, and body weight and brain weight across several species of mammals. These relationships may not hold within species, so the formulas cannot legitimately be applied to race differences. The originator of these formulas (Jerison, 1963) himself wrote ' $\mathrm{L}$... that no inference from the present argument can be drawn about differences in brain weight ... among races of a single species including the races of man" (p. 273). Tobias (1970) recognized and discussed this limitation of the formulas, but calculated excess neurons "purely to emphasize the need for body-size to be taken into account in discussions of human brain-sizes ..." (p. 9). Moreover, Tobias (1970) presented strong arguments against the validity of existing data on race differences in brain size-including the data he used to calculate race differences in excess neurons. Thus, Rushton used as support for his hypotheses data and analyses that his own source argues are invalid.

Finally, Rushton (1989) cited some recent autopsy data showing that blacks have smaller brain weights than do whites (Ho et al., 1980a, 1980b). These data are interesting because they controlled for several of the potentially confounding variables that Tobias (1970) identified as influencing brain weighti.e., sex, body size, age, anatomical level of severance, and presence or absence of cerebrospinal fluid, meninges, and blood vessels. However, Ho et al. controlled for body size by examining the ratios of brain weight/body weight, brain weight/body height, and brain weight/body surface area. The use of these ratios to control for the effects of body size on brain weight assumes that the relationships between brain weight and each body dimension are linear, have zero intercepts, and have similar slopes across the groups being compared. This latter assumption is particularly important because between-group differences on the ratio variables could merely reflect group differences in the slopes of the relationships between brain weight and each body dimension. Ho et al. (1980b) report that these slopes do, in fact, vary considerably between race and gender. This makes their control for body size invalid and their reported race differences uninterpretable. Further confounding the interpretation of these data is Ho et al.'s (1980a, 1980b) failure to report controls for other potential confounds identified by Tobias (1970) i.e.) nutritional state in childhood, nonnutritional childhood environment, cause of death, 
lapse of time after death, and temperature after death. Given these interpretive difficulties, Ho et al.'s data do not "confirm the reality" of race differences in brain size.

\section{Functional Relationships with Reproduction}

Rushton and Bogaert (1987) predicted numerous race differences on what they considered rand K-selected traits. I criticized them for failing to demonstrate that the observed race differences were functionally related to reproduction (as they should be if they reflect differences in $\mathrm{Y}$ and $\mathrm{K}$ reproductive strategies). I also pointed out that human sexuality is thought to enhance pair-bonding and that sexual restraint could therefore be considered an $r$ rather than a K attribute (Lynn, 1989). Rushton (1989) responded by reiterating that there are race differences in egg production (with greater egg production defining an $r$ strategy), by claiming that the other race differences were predicted on the basis of this difference in egg production, and by introducing new evidence of race differences in fecundability. None of these points are responsive to my criticism and the last point is incorrect in any case.

Unresponsiveness of Rushton's Points

Rushton's (1989) arguments about race and reproduction were not responsive to my criticism. I agree with Rushton that egg production is a measure of reproductive effort and that the production of numerous eggs is an r-selected trait. However, the use of differences in egg production to predict other race differences merely begs the question of whether those other race differences are relevant to the $\mathrm{r} / \mathrm{K}$ continuum. The predictions assume, but do not prove, that these other race differences are functionally related to reproduction. This assumption is questionable (see Lynn, 1989) and needs independent empirical support. Observation of the predicted race differences (even if real) would not support this assumption since environmental causes could explain the race differences without assuming their relationships to reproduction or the $\mathrm{r} / \mathrm{K}$ continuum. Nor does Rushton's claim of race differences in fecundability provide the needed support, because there is no evidence that this claimed difference in fecundability is due to the other predicted race differences in sexual behavior, maturation rate, size of genitalia, and secondary sexual characteristics. Thus, my original criticism is unanswered.

Race Differences in Fecundability

Rushton (1989) argued for race differences in fecundability by introducing new data on the delay in child birth among married U.S. couples, the rate of illegitimate pregnancies in the United States, and the rates of reproduction among Third World countries. He claims these data indicate that for fecundability blacks $>$ whites $>$ Orientals. The problem with this claim is that pregnancy and 
reproduction are affected by many factors other than biological fecundity. Consistent with an environmental explanation for Rushton's data on race differences in reproduction is the fact that Brazil's race differences are in exactly the opposite direction. In Brazil, the fertility ratio (i.e., the number of children aged 0 to 4 per woman age 15 to 44 ) increases from blacks (55.6), to whites (65.3), to Orientals (79.7) (Saunders, 1958). One measure of biological fecundity is the rate of natural infertility. This measure also fails to support Rushton's theory because natural infertility rates in the United States are higher for blacks than for whites (13 vs 8 per 1000; U.S. Department of Commerce, 1987). Thus, Rushton's claim that blacks are more fecund than whites who are more fecund than Orientals is not supported by data.

Intelligence as a K Characteristic

Rushton and Bogaert (1987) considered intelligence a K-selected trait and Rushton (1989) devotes a great deal of space to discussions of this variable. Intelligence is $\mathrm{K}$ selected because there is a general tendency for more intelligent species (like apes and humans) to have more prolonged infancies. In turn, prolonged infancies require more parental care and fewer offspring. However, precocity is positively, not negatively, associated with later intelligence among humans (Broman, Nichols, \& Kennedy, 1975; Willerman \& Fiedler, 1974). Thus, my (1989) argument about functional relationships at the between-species level not being valid at the within-species level is supported by this example. Unfortunately, Rushton chose not to address this criticism in his response.

\section{Environmental versus Genetic Causes of Race Differences}

Rushton and Bogaert's (1987) evolutionary hypothesis about race differences in sexuality represents a genetic explanation for these claimed race differences. I criticized these authors for failing to discount environmental explanations for their data (Lynn, 1989). Rushton (1989) responded by repeating some of his and Bogaert's $(1987,1988)$ arguments and by discussing evidence for the heritability of race differences in intelligence. The weaknesses of these responses are discussed below. Heritability of Race Differences in Sexuality

Rushton (1989) presented no new evidence for a genetic cause of race differences in sexuality. Instead, he overlooked my (1989) criticisms and merely repeated his original arguments. For example, Rushton argued that race differences in sexuality were shown to be independent of education level or social class. This ignored my criticism of the adequacy of his control for environmental factors. Similarly, Rushton argued that many aspects of sexuality are heritable and, therefore, that it was reasonable to 
assume some of the race differences in sexuality were genetic in origin. This ignored my objection that within-group heritability need not imply between-group heritability. Rushton has yet to support his claim of a genetic origin for race differences in sexuality.

Heritability of Race Differences in $1 Q$

Rushton (1989) did go beyond his and Bogaert's $(1987,1988)$ articles by reviewing evidence for a genetic explanation of race differences in IQ. The facts that Rushton argued to support the heritability of race differences in intelligence were (a) black children adopted by white families have lower IQs than the families' natural children; (b) Japanese immigrants enjoy educational success despite their minority status; (c) within-family environmental factors affect intelligence more than do between-family environmental factors; (d) the factor loadings of tests on $g$ are the same when calculated both within and between families; (d) the siblings of black and white children matched for IQ regress back halfway to their racial population means; and ( $f$ ) inbreeding depression scores among the Japanese predict the magnitude of black-white differences in IQ. Each of these points is discussed below.

First, Starr and Weinberg (1976) reported that black children adopted by white families scored below the mean of the families's natural children. Rushton (1989) indicated that a 10-year follow-up shows this IQ gap between adopted black children and natural white children to be widening. These data would support a genetic basis for race differences in IQ only if two things were true-i.e., if the adopting families provided their adopted black and natural white children the exact same environments and if the adopted black and natural white children were each genetically representative of their respective racial populations. Neither of these conditions were met. White families that adopt black children cannot give their adoptive children "white" environments because the children still have black skin. Since black-white differences in IQ are widely recognized, it is likely that adopted black children are expected by their adoptive parents, teachers, and peers to perform more poorly than white children (Baron, Tom, \& Cooper, 1985). Such expectations have been shown to be a powerful source of selffulfilling prophecies (Rosenthal \& Jacobson, 1969; Rosenthal, 1985). Furthermore, families who adopt children tend to be more educated and tend to have higher socioeconomic statuses than the population at large. The natural children of these families probably have above average genetic ability for their race. Thus, these natural children are not the appropriate comparison group for adopted black children who presumably have average genetic ability for their race. When the adopted Black children in Starr and Weinberg's (1976) study were compared to the White population at large they had superior IQ scores. Of course, this is also an unfair comparison because adoptive families provide above average 
environments. The point is that adoption studies provide no evidence for race differences in genetic ability.

Second, Japanese and Chinese Americans generally perform at or above white levels on IQ tests and they are overrepresented in professional jobs (see Vernon, 1979; Willerman, 1979). Rushton (1989) attributed this success to superior genes that allow Orientals to overcome their minority status. Presumably, blacks' inferior genes prevent them from doing the same. This conclusion is obviously not justified by the data. Japanese and Chinese Americans differ from black Americans both historically and culturally as well as genetically, so evidence of differences in intellectual and occupational attainment could be due to any number of factors. Inconsistent with Rushton's genetic interpretation of these data is the fact that North American Indians do not share the success of other Mongoloids in America. Although American Indians perform relatively well on nonverbal tests, they score well below white means on verbal and educational tests and are underrepresented in most professional occupations (see Vernon, 1979; Willerman, 1979). Historical and cultural explanations provide a better account of this fact than does Rushton's theory of race differences in genetic ability.

Third, Plomin and Daniels (1987) noted that the cognitive abilities of adoptive siblings no longer living at home were not correlated and they concluded that shared environment (like SES, parental IQ, parenting style, etc.) has little impact on adult intelligence. Rushton (1989) correctly pointed out that this conclusion undermines environmental explanations for race differences in IQ. However, Plomin and Daniels' conclusion was based on the results of only two studies with small samples. Moreover, the range of shared environments among families that adopt is too restricted to test the effects of SES and other shared environments on IQ (Boomsma, 1987). In a study that involved a wider range of socioeconomic conditions, Schiff et al. (1978) found that adopted children reared in high socioeconomic environments had higher IQ scores ( 110.6 vs 94.7$)$ and less failure in school ( $13 \%$ vs $55 \%$ ) than did their full- or half-brothers reared by their natural mothers in low socioeconomic environments. Clearly, shared environment can have a substantial impact on intelligence.

Fourth, Jensen (1980) and Nagoshi, Phillips, and Johnson (1987) have found that the loadings of different tests on $g$ are similar when calculated both within and between families. These factor loadings on g were also similar across race. Rushton (1989) argued that these results mean that race differences in $g$ are not due to between-family factors like SES, cultural background, etc. However, Rushton's logic is faulty; these results have no such implication. The fact that the factor loadings of various tests on $g$ are constant across within- and between-family analyses means only that the relationships between the tests are independent of social class and other between-family factors. In other words, the relationship 
between memory and mathematical ability (as one example) is the same whether people are black, white, rich, or poor. This says nothing about how being black, white, rich, or poor affects the absolute levels of memory and/or mathematical ability.

Fifth, Rushton (1989) summarized a study finding that the siblings of black and white children matched on IQ tended to regress halfway to their respective population means. In other words, the black children showed larger regression effects than did the white children when their siblings' IQs were above average and they showed smaller regression effects than did white children when their siblings' IQs were below average. Rushton claims that this result supports a genetic explanation for race differences in intelligence. He is wrong, because, as Thoday (1973) writes, “....populations must regress to their own mean whatever the cause, genetic or environmental, of the mean differences between the populations" (p. 419). Nevertheless, it is worthwhile evaluating this claim in more detail.

The implicit logic underlying Rushton's claim is as follows: (a) the children matched on IQ are genetically comparable to one another; (b) the siblings of these children share essentially the same environment but only half the genes of these children, so the regression of the siblings' IQs is largely genetic in origin; (c) race differences in the size of the regression effects reflect population differences in mean IQ; therefore, (d) these population differences are genetic in origin. This argument can be challenged on the grounds that relatives do not share the exact same environments, so regression effects could be due to either environmental or genetic differences between the relatives (cf. Loehlin, Lindzey, \& Spuhler, 1975; Scan--Salapatek, 1972). However, this criticism does not account for the accuracy of precise genetic predictions (Vernon, 1972).

Another criticism can account for this precision. It seems unlikely that black and white children matched on IQ are genetically comparable, because blacks generally come from more impoverished environments. Thus, blacks matched with high IQ whites are probably genetically superior because they had to overcome their environmental disadvantage. Similarly, blacks matched with low IQ whites are also probably genetically superior because whites with low IQs had to sink below their environmental advantage. This difference in the genetic abilities of the black and white children matched on IQ would produce the regression effects predicted by genetic theory when the genetic abilities of blacks and whites were equal. Thus, given the above assumption, regression effects support the genetic equality of blacks and whites.

Finally, Kamin (1980) reviewed studies of first cousin marriages and of incestuous matings and found no convincing evidence of inbreeding depression on IQ. Thus, Rushton's (1988) unpublished use of inbreeding depression scores on tests taken in the 1950s to predict black-white differences on IQ in 
the 1970s must be viewed cautiously. Even accepting Rushton's data and analyses, however, this result provides no support for a genetic origin of race differences in IQ. Inbreeding depression can at best provide evidence of within-group heritability. As I pointed out earlier, within-group heritability does not imply between-group heritability. That Rushton's estimates of heritability predict the magnitude of Black- White differences in IQ may be a coincidence-it is certainly not evidence that the race differences are genetic in origin.

\section{Summary}

Rushton's (1989) response to my criticisms of his articles with Bogaert $(1987,1988)$ failed to address many of my criticisms, contained selective and biased descriptions of relevant literatures, and misrepresented some of the theory and data used. Thus, my original criticisms still stand and are strengthened in this rebuttal. Rushton and Bogaert's $(1987,1988)$ hypothesis about race differences on the $r / K$ continuum should be rejected on four grounds. First, the differences between $r$ and $K$ selection have little effect on large mammals like man. Second, the literature reviews and studies supporting this hypothesis are biased and many nonsupportive studies exist. Third, the hypothesis' assumption that the $\mathrm{r}$ and $\mathrm{K}$ characteristics examined are functionally related to reproduction on a within-species level is implausible and unsupported. Finally, the race differences predicted by this hypothesis can be readily explained by environmental causes.

\section{References}

Barash, D. P. (1977). Sociobiology and behavior. New York: Elsevier.

Baron, R. M., Tom, D. Y. H., \& Cooper, H. M. (1985). Social class, race, and teacher expectations. In J. B. Dusek (Ed.), Teachers expectancies (pp. 251-269). Hillsdale, NJ: Lawrence Erlbaum.

Boomsma, D. I. (1987). Absence or underestimation of shared environment. Behavioral and Brain Sciences, 10, 19-20.

Broman, S. H., Nichols, P. L., 8z Kennedy, W. A. (1975). Preschool Z.Q.: Prenatal and early developmental correlates. Hilsdale, NJ: Lawrence Erlbaum.

Brooks, D. R., \& Wiley, E. 0. (1986). Evolution as entropy: Toward a unified theory of biology. Chicago: University of Chicago Press.

Cooper, H. M. (1984). The integrative research review: A social science approach. Beverly Hills, CA: Sage.

Daly, M., \& Wilson, M. (1978). Sex, evolution and behavior. North Scituate, MA: Duxbury Press. 
Dobzhansky, T. (1950). Evolution in the tropics. American Scientist, 38, 209-221.

Gaertner, S. L., \& Bickman, L. (1971). Effects of race on the elicitation of helping behavior. Journal of Personality and Social Psychology, 20, 218-222.

Gould, S. J. (1981). The mismeasure of man. New York: Norton.

Ho, K.-C, Roessman, U., Straumfjord, J. V., \& Monroe, G. (1980a). Analysis of brain weight. I. Adult brain weight in relation to sex, race, and age. Archives of Pathology and Laboratory Medicine, 104, 635-639.

Ho, K.-C, Roessman, U., Straumfjord, J. V., \& Monroe, G. (1980b). Analysis of brain weight. II. Adult brain weight in relation to body height, weight and surface area. Archives of Pathology and Laboratory Medicine, 104, 640-645.

Jensen, A. R. (1980). Uses of sibling data in educational and psychological research. American Educational Research Journal, 17, 153-170.

Jerison, H. J. (1\%3). Interpreting the evolution of the brain. Human Biology, 35, 262- 291.

Kamin, L. J. (1980). Inbreeding depression and I.Q. Psychological Bulletin, 87, 469-478.

Loehlin, J., Lindzey, G., \& Spuhler, J. (1975). Race differences in intelligence. San Francisco: W. H. Freeman.

Lynn, M. (1989). Race differences in sexual behavior: A critique of Rushton and Bogaert's evolutionary hypothesis. Journal of Research in Personality, 23.

McArthur, R. H., \& Wilson, E. D. (1967). The theory of island biogeography. Princeton, NJ: Princeton University Press.

Nagoshi, C. T., Phillips, K., \&Johnson, R. C. (1987). Between- versus within-family factor analyses of cognitive abilities. Intelligence, 11, 305-316.

O'Grady, R. T. (1982). Nonequilibrium evolution and ontogeny. Systematic Zoology, 31, 503-511.

Pianka, E. R. (1970). On r- and K-selection. American Naturalist, 104, 592-597.

Pianka, E. R. (1978). Evolutionary ecology. New York: Harper \& Row.

Plomin, R., \& Daniels, D. (1987). Why are children in the same family so different from one another? Behavioral and Brain Sciences, 10, 1-60.

Richard, A. F. (1985). Primates in nature. New York: W. H. Freeman.

Rosenthal, R. (1984). Meta-analytic procedures for social research. Beverly Hills, CA: Sage.

Rosenthal, R. (1985). From unconscious experimenter bias to teacher expectancy effects. In J. B. Dusek (Ed.), Teachers' Expectancies (pp. 37-65). Hillsdale, NJ: Lawrence Erlbaum.

Rosenthal, R., \& Jacobson, L. (1\%8). Pygmalion in the classroom. New York: Holt, Rinehart 8 Winston. 
Rushton, J. P. (1985). Differential K theory: The sociobiology of individual and group differences. Personality and Individual Differences, 6, 441-452.

Rushton, J. P. (1988). Japanese inbreeding depression scores: Predictors of cognitive differences between blacks and whites. Unpublished manuscript, University of Western Ontario, London, Canada.

Rushton, J. P. (1989). The evolution of racial differences: A response to Lynn. Journal of Research in Personality, 23.

Rushton, J. P., \& Bogaert, A. F. (1987). Race differences in sexual behavior: Testing an evolutionary hypothesis. Journal of Research in Personality, 21, 529-551.

Rushton, J. P., \& Bogaert, A. F. (1988). Race versus social class differences in sexual behavior: A follow-up test of the r/K dimension. Journal of Research in Personality, 22, 259-272.

Saunders, J. V. D. (1958). Differential fertility in Brazil. Gainesville: University of Florida Press.

Starr-Salapatek, S. (1972). I.Q.: Methodological and other issues-Reply. Science, 178, 235-240.

Starr, S., \& Weinberg, R. A. (1976). IQ. test performance of Black children adopted by White families. American Psychologist, 31, 726-739.

Schiff, M., Duyme, M., Dumaret, A., Steward, J., Tomkiewicz, S., \& Feingold, J. (1978). Intellectual status of working-class children adopted early into upper-middle-class families. Science, 200, $1503-$ 1504.

Thoday, J. M. (1973). Educability and group differences. Nature (London) 245, 418-420.

Tobias, P. V. (1970). Brain size, grey matter and race-Fact or fiction? American Journal of Physical Anthropology, 32, 3-26.

U.S. Department of Commerce. (1987). Statistical abstracts of the United States. Washington, DC: Author.

Vernon, P. E. (1979). Intelligence: Heredity and environment. San Francisco: W. H. Freeman.

Weinberg, M. S., \& Williams, C. J. (1988). Black sexuality: A test of two theories. Journal of Sex Research, 25, 197-218.

Willerman, L. (1979). The psychology of individual and group differences. San Francisco: W. H. Freeman.

Willerman, L., \& Fiedler, M. F. (1974). Infant performance and intellectual precocity. Child Development, 45, 483-486.

Wilson, E. O. (1980). Sociobiology: The abridged edition. Cambridge, MA: Belknap Press.

Wispe, L. G., \& Freshley, H. B. (1971). Race, sex and sympathetic helping behavior: The broken bag caper. Journal of Personality and Social Psychology, 17, 59-65. 
Wyatt, G. E. (in press-a). Why we know so little about Afro-American sexuality. In R. L. Jones (Ed.), Black adult development and aging. Richmond, CA: Cobb \& Henry.

Wyatt, G. E. (in press-b). Re-examining factors predicting Afro-American and White- American women's age of first coitus. Archives of Sexual Behavior. 